patients were older (mean age 71 (SD 12) and 66 (SD 13) years respectively) compared to AS and PsA (mean age 50 (SD 14) and 55 (SD 13) years respectively). When adjusting for these differences by IAS by sex, both prevalent CVD (stroke, ACS) and all traditional risk factors were more common in gout compared to RA, AS or PsA (Table 1+2), except for alcohol intake in women, where highest exposure was seen in PsA (Table 2). The male AS patients displayed the highest PA level and the lowest prevalence of stroke (table 1). Smoking was least common in male PsA and female AS and RA patients (table 1+2).

\begin{tabular}{|c|c|c|c|c|c|c|}
\hline Males & $\begin{array}{c}\text { Gout, } \mathrm{n}= \\
582, \\
\text { prevalence } \\
\%\end{array}$ & $\begin{array}{c}\text { AS, } n= \\
273, \\
\text { prevalence } \\
\%\end{array}$ & $\begin{array}{c}\text { PsA, } \mathrm{n}= \\
268, \\
\text { prevalence } \\
\%\end{array}$ & $\begin{array}{c}\mathrm{RA}, \mathrm{n}= \\
315, \\
\text { prevalence } \\
\%\end{array}$ & p-value* & $\begin{array}{c}\mathrm{GP}, \mathrm{n}= \\
23177, \\
\text { prevalence } \\
\%\end{array}$ \\
\hline $\mathrm{BMI} \geq 25$ & 85.3 & 51.5 & 59.0 & 65.9 & $<0.0001$ & 56.2 \\
\hline PA, low & 61.9 & 44.0 & 54.8 & 58.0 & 0.0001 & 42.5 \\
\hline $\begin{array}{l}\text { Alcohol, } \\
\text { high }\end{array}$ & 43.3 & 20.0 & 28.3 & 16.5 & $<0.0001$ & $N / A$ \\
\hline $\begin{array}{l}\text { Smoking, } \\
\text { ever }\end{array}$ & 48.5 & 53.4 & 35.9 & 46.6 & 0.0003 & $\mathrm{~N} / \mathrm{A}$ \\
\hline DM & 14.2 & 4.8 & 8.4 & 8.7 & 0.0001 & 6.0 \\
\hline HT & 49.2 & 23.9 & 32.9 & 29.2 & $<0.0001$ & 18.7 \\
\hline $\mathrm{DL}$ & 25.3 & 9.6 & 11.2 & 13.1 & $<0.0001$ & $\mathrm{~N} / \mathrm{A}$ \\
\hline Stroke & 7.7 & 0.9 & 4.1 & 4.9 & 0.0005 & N/A \\
\hline ACS & 7.7 & 3.1 & 6.1 & 6.4 & 0.6 & $\mathrm{~N} / \mathrm{A}$ \\
\hline
\end{tabular}

Age-standardized prevalences of CVD riskfactors and outcomes in males, ${ }^{*}$ Chi-square comparing gout, AS, PsA and RA

\begin{tabular}{lcccccc}
\hline Females & $\begin{array}{c}\text { Gout, } \mathrm{n}= \\
134, \\
\text { prevalence } \\
\%\end{array}$ & $\begin{array}{c}\mathrm{AS}, \mathrm{n}= \\
215, \\
\text { prevalence } \\
\%\end{array}$ & $\begin{array}{c}\text { PsA, } \mathrm{n}= \\
305, \\
\text { prevalence } \\
\%\end{array}$ & $\begin{array}{c}\text { RA, } \mathrm{n}= \\
345, \\
\text { prevalence } \\
\%\end{array}$ & p-value* & $\begin{array}{c}\text { GP, } \mathrm{n}= \\
26714, \\
\text { prevalence } \\
\%\end{array}$ \\
\hline BMI $\geq 25$ & 87.3 & 40.8 & 60.0 & 45.9 & $<0.0001$ & 43.1 \\
PA, low & 74.8 & 48.3 & 54.3 & 52.6 & $<0.0001$ & 46.5 \\
Alcohol, & 7.0 & 6.4 & 14.2 & 6.9 & 0.003 & $\mathrm{~N} / \mathrm{A}$ \\
high & & & & & & \\
Smoking, & 56.7 & 37.8 & 56.8 & 38.0 & $<0.0001$ & $\mathrm{~N} / \mathrm{A}$ \\
ever & & & & & & \\
DM & 14.9 & 2.3 & 4.9 & 4.2 & $<0.0001$ & 4.4 \\
HT & 56.8 & 20.3 & 27.5 & 24.4 & $<0.0001$ & 17.6 \\
DL & 26.7 & 7.4 & 10.5 & 9.7 & $<0.0001$ & $\mathrm{~N} / \mathrm{A}$ \\
Stroke & 3.7 & 0.8 & 0.6 & 1.7 & 0.09 & $\mathrm{~N} / \mathrm{A}$ \\
ACS & 3.6 & 0.0 & 1.8 & 2.5 & 0.2 & $\mathrm{~N} / \mathrm{A}$ \\
\hline
\end{tabular}

Age-standardized prevalences of CVD riskfactors and outcomes in females, *Chi-square comparing gout, AS, PsA and RA

Conclusion: Gout patients display the highest prevalence of CVRFs in both men and women compared to AS, PsA and RA. Thus, addressing CVDRFs is of particular importance in patients with gout.

Disclosure of Interests: Mats Dehlin: None declared, Ulrika Bergsten: None declared, Eva Klingberg Grant/research support from: Unrestricted grant from Roche, Consultant for: Novartis, Speakers bureau: Speakers fee from Lilly, Anton Landgren: None declared, Lennart T.H. Jacobsson Consultant for: LJ has received lecture and consulting fees from Pfizer, Abbvie, Novartis, Eli-Lily and Janssen

DOI: 10.1136/annrheumdis-2019-eular.1131

\section{AB1258 THE 10 YEAREXPERIENCE OF IDENTIFYING AND MONITORING INDIVIDUALS AT RISK OF RA IN AN ARTHRITIS PREVENTION CLINIC}

Laurence Duquenne $^{1,2}$, Kulveer Mankia ${ }^{1,2}$, Jacqueline $\mathrm{Nam}^{1,2}$, Leticia GarciaMontoya $^{1,2}$, Peta Pentony ${ }^{1,2}$, Andrea Dimatteo $^{1,2}$, Laura Hunt ${ }^{1,2}$, Paul Emery $^{1,2}$. ${ }^{1}$ Leeds Institute of Rheumatic and Musculoskeletal Medicine, Leeds, United Kingdom; ${ }^{2}$ NIHR Leeds Biomedical Research Centre, Leeds, United Kingdom

Background: Anti-cyclic citrullinated protein antibodies (anti-CCP) are highly specific for rheumatoid arthritis (RA) and may appear more than 10years before the disease. As the test has become more accessible, many patients without clinical synovitis are being globally tested.

Objectives: We have developed in Leeds a prevention study clinic for referrals from individuals identified through our primary care research network alongside the patients from secondary care referrals, aiming for an early identification of inflammatory arthritis (IA)[1].

Methods: From June 2008 to December 2018, individuals from our primary care network with new musculo-squeletal symptoms were invited to be tested. All anti-CCP tests were performed centrally in our Rheumatology Department in Leeds (LIRMM), using a standard Anti-CCP2 assay (immunocap method, Phadia assay). Individuals from primary or secondary care who were tested positive for anti-CCP antibodies (CCP positive) were invited to Leeds and followed prospectively in a research, observational study until progression to IA.

Results: As shown in figure 1, the number of patients referred to our study from either primary or secondary care has been increasing gradually. Over the last year, the overall referrals reached 2368 participants, 115 of them from secondary care and 2253 from primary care.

Of the 901 CCP positive individuals, 479 met the inclusion criteria and accepted to participate to the study (Table 1). Actually, the mean followup time of the overall cohort is 98.5weeks (SD 105.55) with a cumulative time of follow-up of over 50000 weeks. There is a female predominance of $72.1 \%$ and a mean age of 50.3 years (SD 13.51) at baseline. Of the 165 participants that have been withdrawn from the study, 134 developed IA after a mean time of 83.8 weeks (28.0\% of the overall cohort). Currently, 353 anti-CCP positive patients are still being followed. Age and sex of the patients who progressed are similar to the ones still in the study (respectively $\mathrm{p}=0.798$ and $\mathrm{p}=0.326$ ).

Conclusion: Leeds Teaching Hospital and LIRMM have now been following patients at risk of progressing to $\mathrm{IA}$ for more than 10 years. The steady increase in recruitment from both primary care and secondary care centres confers a viable base for recruitment. As prevention is a key aspect in global Health management, our study is a sustainable model for identifying at-risk subjects of progression, a necessary step towards prevention. This increase in overall referrals correlates with a need of recommendation regarding management of patients, especially those at high risk.

\section{REFERENCES}

[1] Hunt, L. and P. Emery, Defining populations at risk of rheumatoid arthritis: the first steps to prevention. Nat Rev Rheumatol, 2014. 10(9): p. 521-30.

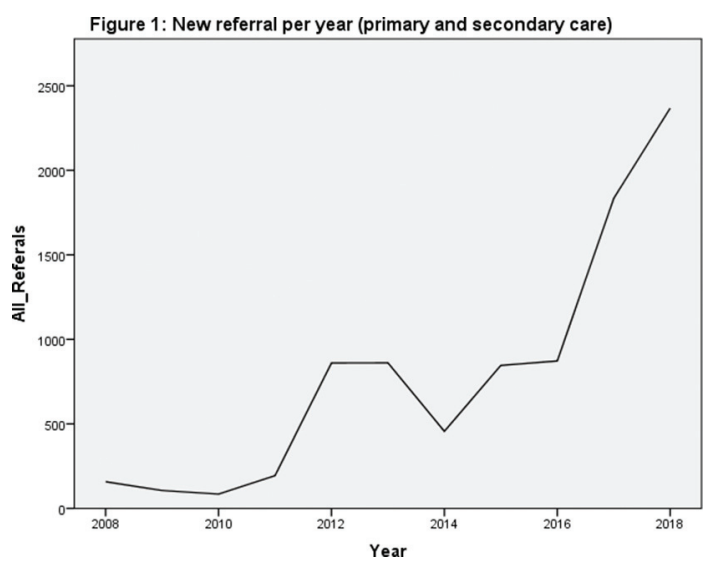

Figure 1

Table 1. Demographics

\begin{tabular}{|c|c|c|c|}
\hline & Overall cohort & $\begin{array}{c}\text { Progressors } \\
\text { (84\% of total withdrawn } \\
(n=165))\end{array}$ & Ongoing follow-up \\
\hline $\mathrm{N}$ & 479 & $136(26.1 \%)$ & 314 \\
\hline $\begin{array}{l}\text { Mean follow-up } \\
\text { (weeks) }\end{array}$ & 98.5 (SD 105.55) & 83.83 (SD 90.87) & $\begin{array}{c}105.72 \\
(\mathrm{SD} 111.65)\end{array}$ \\
\hline \multirow[t]{3}{*}{ CCP titre } & $\begin{array}{l}\text { High: } 59.9 \% \\
\text { ( } n=288) \\
\text { Low: } 36.4 \%\end{array}$ & $\begin{array}{l}\text { High: } 89.7 \%(n=122) \\
\text { Low: } 9.6 \%(n=13) \\
\text { RF control: } 0.7 \%(n=1)\end{array}$ & $\begin{array}{c}\text { High: } 49.4 \% \\
(n=155) \\
\text { Low: } 49.4 \%\end{array}$ \\
\hline & $\begin{array}{c}\text { Low: } 36.4 \% \\
\quad(n=175)\end{array}$ & RF control: $0.7 \%(n=1)$ & $\begin{array}{l}\text { Low: } 49.4 \% \\
\quad(n=155)\end{array}$ \\
\hline & $\begin{array}{c}\text { Neg: } 3.11 \% \\
\quad(n=15)^{\star}\end{array}$ & & Neg: $1.3 \%(n=4)$ \\
\hline \multirow[t]{2}{*}{ Gender } & F $72.1 \%(n=347)$ & F 68.4\% (n=93) & F 72.9\% (n=229) \\
\hline & M $27.9 \%(n=134)$ & M $31.6 \%(n=43)$ & M 27.1\% (n=85) \\
\hline Age & $50.34(\mathrm{SD} 13.51)$ & 52.8 (SD 13.05) & $49.84(\mathrm{SD} 13.56)$ \\
\hline
\end{tabular}

Disclosure of Interests: Laurence Duquenne: None declared, Kulveer Mankia Grant/research support from: Research support from BMS and Lilly, Speakers bureau: Honoraria from Abbvie, UCB, Jacqueline Nam: None declared, Leticia Garcia-Montoya: None declared, Peta Pentony: None declared, Andrea DiMatteo: None declared, Laura Hunt: None declared, Paul Emery Grant/research support from: Pfizer, MSD, AbbVie, Bristol-Myers Squibb, Roche, Consultant for: Pfizer, MSD, AbbVie, BristolMyers Squibb, UCB, Roche, Novartis, Gilead,Samsung, Sandoz and Lilly 


\section{AB1259 EVALUATION OF ENALAPRIL ON ARTERIAL STIFFNESS IN RHEUMATOID ARTHRITIS IN A RANDOMISED CLINICAL TRIAL}

Felipe Perez-Vazquez ${ }^{1}$, Sergio Duran Barragann ${ }^{2}$, Eduardo Gomez-Bañuelos ${ }^{1,3}$ Efrain Chavarria Avila ${ }^{1}$, Carlos Ramos Becerra ${ }^{4}$, Gustavo-Ignacio Diaz-Rubio ${ }^{5}$, Mario Salazar-Paramo ${ }^{4}$, Fernando Grover Páez ${ }^{4}$, Arnulfo Hernán Nava-Zavala ${ }^{4}$, Ernesto G. Cardona-Muñoz ${ }^{4}$, David Cardona Müller ${ }^{4}$, Rosa E. NavarroHernández ${ }^{5}$, Valeria-Nicole Mera-Riofrio ${ }^{5}$, Natalia Prado-Bachega ${ }^{5}$, Monica Vazquez-Del-Mercado ${ }^{5} .{ }^{1}$ Instituto de Investigación en Reumatología y del Sistema Músculo Esquelético, Departamento de Biología Molecular y Genómica, Guadalajara, Mexico; ${ }^{2}$ Hospital Civil Dr. Juan I. Menchaca, Servicio de Reumatología PNPC 004086 CONACyT, Guadalajara, Mexico; ${ }^{3}$ Universidad de Guadalajara, Centro Universitario de Ciencias de la Salud, Instituto de Investigación en Reumatología y del Sistema Músculo Esquelético, Departamento de Biología Molecular y Genómica, Guadalajara, Mexico; ${ }^{4}$ Universidad de Guadalajara, Centro Universitario de Ciencias de la Salud. Instituto de Terapéutica Experimental y Clínica, Departamento de Fisiología, Guadalajara, Jalisco, México, Guadalajara, Mexico; ${ }^{5}$ Universidad de Guadalajara, Centro Universitario de Ciencias de la Salud, Instituto de Investigación en Reumatología y del Sistema Músculo Esquelético, Departamento de Biología Molecular y Genómica, Guadalajara, Mexico

Background: This is the first study where suboptimal doses of enalapril proved to be successful for the reduction of arterial stiffness in in a clinical trial of rheumatoid arthritis (RA) patients.

Objectives: The aim of this study was to analyze the effect of enalapril on arterials stiffness through the evaluation of subclinical parameters in RA patients without traditional cardiovascular risk factors or previous comorbidities. Methods: Fifty three patients were enrolled in a clinical, randomized, closed-label trial. The subjects were randomly assigned into two groups: One receiving $5 \mathrm{mg}$ of enalapril (27) and $5 \mathrm{mg}$ of placebo (26), both twice a day. Clinical assessment included a structured questionnaire to gather demographic and clinical variables, including disease duration, treatment, disease activity, laboratory, anthropometric measurements and determination of cardiovascular parameters [carotid femoral pulse wave velocity (cfPWV) (1), cardio-ankle vascular index (CAVI) (2), carotid intima media thickness (cIMT), carotid artery distensibility (3), Young's incremental elastic modulus (Einc)]. The whole set of evaluations were analyzed at the baseline and at the end of 12 weeks of intervention.

Results: A significant reduction in delta CAVI of 0.21 in the enalapril intervention group was found. In contrast, an increase of 0.39 was observed in the placebo group. The delta CAVI reduction was not influenced by age or peripheral systolic blood pressure (pSBP).

Conclusion: Enalapril seems to be effective in CAVI reduction in RA patients. The effect of enalapril intervention on arterial stiffness translated to the clinical context, might be interpreted as a reduction of 6.4 years of arterial aging

\section{REFERENCES}

[1] Vazquez-Del Mercado, M., et al., Disease duration of rheumatoid arthritis is a predictor of vascular stiffness: a cross-sectional study in patients without known cardiovascular comorbidities: A STROBE-compliant article. Medicine (Baltimore), 2017. 96(33): p. e7862.

[2] Saiki, A., et al., The Role of a Novel Arterial Stiffness Parameter, CardioAnkle Vascular Index (CAVI), as a Surrogate Marker for Cardiovascular Diseases. J Atheroscler Thromb, 2016. 23(2): p. 155-68.

[3] Vazquez-Del Mercado, M., et al., Subclinical parameters of arterial stiffness and arteriosclerosis correlate with QRISK3 in systemic lupus erythematosus. PLoS One, 2018. 13(12): p. e0207520.

Disclosure of Interests: None declared

DOI: 10.1136/annrheumdis-2019-eular.8241

\section{AB1260 CHARACTERISTICS OF METABOLIC SYNDROME IN AN ASIAN COHORT OF PATIENTS WITH RHEUMATOID ARTHRITIS}

Claire Teo Min-LI' Elampirai Elangovann², Chia Mun Woo ${ }^{3}$, Chien Joo Lim³ ${ }^{3}$, Khai Pang Leong ${ }^{1}$, Ee Tzun Koh ${ }^{1} .{ }^{1}$ Tan Tock Seng Hospital, Rheumatology, Allergy and Immunology, Singapore, Singapore; ${ }^{2} \mathrm{MOH}$ Holdings Pte Ltd, Singapore, Singapore; ${ }^{3}$ Tan Tock Seng Hospital, CMB - Clinical Research and Innovation Office, Singapore, Singapore

Background: Metabolic syndrome (MS), the concurrence of hypertension, abdominal obesity, dyslipidemia and glucose intolerance, is an important risk factor for type II diabetes mellitus (T2DM) and cardiovascular disease
(CVD). CVD is a leading cause of morbidity and mortality in patients with rheumatoid arthritis (RA). Studies in RA suggest that inflammation and glucocorticoid use predispose to MS, and that MS is associated with active disease.

Objectives: To investigate the prevalence and characteristics of MS in our cohort of RA patients.

Methods: A total of 409 patients who fulfilled the 1987 ACR criteria for RA and with complete data for classification of MS were included. MS was defined according to the Adult Treatment Panel III report of the National Cholesterol Education Programme (NCEP/ATP III). Information related to demographics, disease onset, serologies, disease activity and treatment was collected. Independent t-test or Mann-Whitney $U$ test was used to compare continuous quantitative data, while Pearson Chi-square or Fisher Exact test for categorical data. Logistic regression was used to identify factors associated with of MS. All the statistical tests were two sided, and $p$ value $<0.05$ was considered as statistically significant.

Results: Fifty-two patients (12.7\%) fulfilled the criteria for MS. Most of the patients in the cohort were female $(85.3 \%)$ and non-smokers $(84.6 \%)$. The mean age was $60.5 \pm 11.09$ years and mean BMI $23.67 \pm 5.06$. The patients with MS were significantly older (age $64.21 \pm 8.63$ vs $59.96 \pm 11.32$, $\mathrm{p}=0.010$ ). The mean disease duration was $14.09 \pm 9.74$ years. Rheumatoid factor and anti-cyclic citrullinated peptide antibody were present in $80.0 \%$ and $95.1 \%$ respectively. $4.4 \%$ of them had a history of CVD or stroke/ transient ischaemic attack but the prevalence was the same in patients with and without MS. Comparing the two groups, there was no significant difference in the history of ever-smoking ( $15.4 \%$ vs $15.4 \%, p=0.699)$, disease duration ( $16.44 \pm 10.11$ vs $13.72 \pm 9.66$ years, $p=0.060)$, cumulative glucocorticoid use $(p=0.649)$, DAS28 score $(2.12 \pm 1.09$ vs $2.11 \pm 1.24$ $\mathrm{p}=0.458)$ and $\mathrm{HAQ}$ score $(0.13$ vs $0.13, \mathrm{p}=0.767)$. There was also no significant difference in the use of methotrexate, leflunomide or biologics. The commonest MS criteria fulfilled were hypertension (88.5\%) and dyslipidaemia (84.6\%). $46.2 \%$ of the patients with MS had T2DM. Males were less likely to have MS than females [adj. OR $(95 \% \mathrm{Cl}): 0.039(0.005$, 0.292), $\mathrm{p}=0.002$.

Conclusion: MS is found in $12.7 \%$ of our RA patients and they were significantly older than those without MS. In our study, MS does not have a significant association with RA disease activity, disease duration, glucocorticoid usage or disease modifying anti-rheumatic treatment.

\section{REFERENCES}

[1] Rostom S, et al. Metabolic syndrome in rheumatoid arthritis: case contro study. BMC Musculoskeletal Disorders. 2013 Apr 26;14:147.

[2] Tantayakom P, et al. Metabolic syndrome is associated with disease activity in patients with rheumatoid arthritis. Joint Bone Spine. 2016 Oct;83 (5):563

Disclosure of Interests: None declared DOI: 10.1136/annrheumdis-2019-eular.3070

\section{AB1261 CADMIUM TOXICITY AS A PROBABLE CAUSE OF OSTEOPENIA IN ADOLESCENTS AND ITS RELATION TO BAD DIETARY HABITS}

Adel Elbeialy ${ }^{1}$, Hesham Eldesouky ${ }^{2} .{ }^{1}$ Al-Azhar Faculty of Medicine, Rheumatology, Cairo, Egypt, ${ }^{1} \mathrm{Al}$-Azhar Faculty of Medicine, Rheumatology, Cairo, Egypt

Background: Cadmium is a naturally occurring minor element; it has been recognized as an occupational health hazard for many decades. Water and food are the main source of environmental cadmium exposure in non-smokers in most parts of the world. Cadmium accumulates gradually in the human body, where it gives rise to a number of adverse health effects and especially to kidney and bone. Several studies have addressed a possible association between long-term low-level environmental cadmium exposure and osteoporosis. Osteoporosis is a large and escalating public health problem.

Objectives: This study was conducted to assess the bone mineral status in secondary school students in Egypt and to measure cadmium level in their blood and urine and possible relationship between cadmium retention and bone mineral abnormalities as well as its consumption from some food and drinks commonly utilized by those students.

Methods: Two hundred secondary school students from different secondary schools in Egypt were included in this study $(100$ males, and 100 females). Bone mineral status was assessed in the 200 students by Quantitative Ultrasonography (QUS) of the calcaneus using the ultrasound bone densitometer unit PEGASUS PRESTIGE, OSTEOMED, FRANCE. Students with abnormal bone mineral status ( $T$ score $<-1$ ) were considered osteopenic, data obtained from this osteopenic group were compared 